\title{
Microbial quality of ready-to-eat vegetable salads vended in the central business district of Tamale, Ghana
}

\author{
Godwin Abakari, Samuel Jerry Cobbina and Enoch Yeleliere*
}

\begin{abstract}
Background: Food safety problems still persist across the globe and remain a challenge to the general public and government. The study determined the microbiological quality of pre-cut vegetable salads sold in the Central Business District (CBD) of Tamale.

Results: A total of thirty (30) salad samples were purchased from four zones of the District and transported to the Spanish Laboratory of the University for Development Studies, Ghana for analysis. Standard microbiological methods that are in accordance with American Public Health Association (APHA) were used in determining the presence and levels of bacteria in the salad samples. Escherichia coli were detected in $96.7 \%$ of salad samples with levels ranging from 0 to $7.56 \log 10 \mathrm{cfu} / \mathrm{g}$. Bacillus cereus were present in $93.3 \%$ of ready-to-eat vegetable salads with counts ranging from 0 to $7.44 \log 10 \mathrm{cfu} / \mathrm{g}$. Further, Salmonella spp. and Shigella spp. were present in $73.3 \%$ and $76.7 \%$ of salads, respectively.

Salmonella spp. and Shigella spp. counts ranged from 0 to $4.54 \log 10 \mathrm{cfu} / \mathrm{g}$ and 0 to $5.54 \log 10 \mathrm{cfu} / \mathrm{g}$, respectively. Statistically, Escherichia coli, Bacillus cereus and Shigella spp. Contamination varied significantly $(p<0.05)$ across the four zones demarcated. However, Salmonella spp. contamination did not vary significantly $(p>0.05)$ across the zones.

Conclusions: The study revealed that salads sold by street food vendors in the CBD of Tamale were unwholesome for human consumption and could be deleterious to the health of consumers. The contamination could be attributable to the source of production of the vegetables and improper food handling. It is recommended that the Food and Drugs Authority should enforce strict compliance to food quality standards at all food vending establishments in the CBD.
\end{abstract}

Keywords: Ready-to-eat, Salads, Tamale, Salmonella spp., Shigella spp., Escherichia Coli, Bacillus cereus

\section{Background}

Food safety has become a serious concern and a major focus for many scientists in recent years. Also, the interest of the public on food safety issues is on the ascendancy worldwide (WHO/FAO, 2015). Nonetheless, food safety problems continue to persist across the globe and remain a great challenge (Ntuli et al., 2017). It has been established that the business of food vending has created jobs and contributes significantly to the informal sector of the economies of most countries across the globe and as well resolves serious issues confronting major social problems in less developed countries due to the sector's

\footnotetext{
* Correspondence: enochyeleliere.ye@gmail.com

Department of Ecotourism and Environmental Management, Faculty of

Natural Resources and Environment, University for Development Studies, Tamale, Ghana
}

role of providing inexpensive meals to consumers (Alimi et al., 2016). Notably, Estrada-Garcia et al. (2002) reported that in 1998 approximately $28.5 \%$ of the work force in Mexico were said to be employed in the informal sector, in addition $30.8 \%$ of the Informal sector's activities were in the food vending business employing about 120,000 people. It is worth noting that, the activities of most food vendors and practitioners especially street food vendors usually go on unregulated mainly due to negligence and lack of enforcement of the laws governing food safety resulting in serving unwholesome foods to the populace (Alimi et al., 2016).

The consumption of vegetables and vegetables products are vital for the total health of every individual, however, microbial contamination of these vegetables has become a serious challenge deserving of greater 
attention. Globally, Salad vegetables are one group of vegetables which are a major component of food vending and mostly implicated in this regard.

Salads are fresh vegetables which require minimal washing and processing and cut into desired shapes and sizes with knives or other shredding utensils and usually serve as along with other foods including rice (Ababio and Lovatt, 2014). Worldwide, salad vegetables are considered a major source of nutrients for people and particularly as sources of cancer fighting agents for the skin (Ramteke et al.,2016). Recent studies have established that consumption of salad vegetables can prevent heart diseases and skin cancers (Coulibaly-Kalpy et al., 2017).

Salad vegetables are mostly consumed due to their nutritious components as well as their gustatory attributes when consumed in combination with other foods, which is sometimes as result of the culinary prowess of the food vendors (Choudhury et al., 2011; Alimi et al., 2016).

Salads are also sources of vitamins, minerals, proteins and relevant nutritional components for the proper functioning of the human body (Amoah, 2014). However, ready to eat food like vegetable salads are major potential sources of entropathogens and food borne illness (Mensah et al., 2002). Feglo and Sakyi (2012) recorded various levels of Staphylococcus aureus, Bacillus species, Klebsiella pneumoniae, Escherichia coli in different ready-to-eat foods in the Kumasi metropolis of Ghana. Salmonella, Shigella, Escherichia coli (E. coli), Clostridium, Staphylococcus, Campylobacter, and Vibrio are some of the common bacteria that cause food-related illness (Amoah, 2014).

Mensah et al. (2002) examined 511 ready to eat food in Accra and reported the presence of mesophilic bacteria, Bacillus cereus, E. coli, Staphylococcus aureus, Enterobacteriaceae and Shigella sonnei in most ready to eat foods. Similarly, bacteria such as Salmonella species, Staphylococci aureus and Escherichia coli, which can be conveyed by food, cause food poisoning and food-borne illness such as tuberculosis, typhoid fever and cholera (Foskett et al., 2003).

Bruce et al. (2005) reported that diarrhoea diseases are the major causes of hospital attendance in Ghana. Studies conducted in Kumasi have also identified vegetables prepared by food vendors especially the street food vendors to be highly contaminated with faecal material and harmful micro-organisms (Amoah et al., 2006) and several related risk practices of food handling have been identified by Henseler (2005) and Olsen (2005).

The most predominant bacteria in Ghanaian foods are Enterobacter spp., Citrobacter spp., Klebsiella spp. and Escherichia spp. which were found to be present in 65, 50, 46 and $38 \%$ respectively, of the food samples considered in the studies analysed (Saba and Gonzalez-Zorn, 2012).

Research conducted in the international front on bacteria contamination show series of outbreaks. In India,
Sabbithi et al. (2014) reported the microbial quality of salads served along with street foods in Hyderabad from which he recovered Salmonella spp., Staphylococcus aureus and Yersinia at unacceptable levels and for which the source of contamination was attributed to the unhygienic practices of food vendors after HACCP was conducted on the vendors. Moreover, De Oliveira et al., 2011 also examined the microbial contamination of 162 samples of minimally processed ready-to-eat vegetables in Brazil were Salmonella spp., Escherichia coli, Psychrophilic aerobic bacteria, total and thermotolerant coliforms and Listeria spp. were recorded at levels above WHO recommended limits. The various microbial contaminations have caused serious health implications when ingested by consumers. Annually, about a million cases of foodborne salmonella illness is reported in U.S, and about 19,000 hospitalizations and 380 death cases are reported every year (CDC, 2014). It is reported that listeria can cause listeriosis a serious and deadly foodborne illness that can be dangerous when ingested especially by pregnant women, fetuses and embryos including individuals with a weakened immune system (Centre for Disease Control and Prevention, 2008). The Centre for Disease Control and Prevention (2008) has described microbial contamination of ready-to-eat foods as a public health concern and usually in the developed countries, especially the U.S, products of vegetable origin are most usually recalled due to the presence of bacteria that are of public health concern.

Though, a number of studies have been carried out on microbial quality of vegetables and other foods, there is a paucity of information on the microbial quality and safety of precut salads served at food joints in the Central Business District (CBD) of Tamale, Ghana. Hence, the present study on the microbial quality of precut salads in the CBD is timely and provides information on the safety of consuming ready-made salads at food joints.

\section{Methods}

\section{Study area}

The study was conducted in the Central Business District which is the heart of the Tamale Metropolis of Ghana where most business activities take place. The Tamale Metropolitan area is located geographically between latitudes $09^{\circ} 24^{\prime} 27^{\prime \prime}$ and $9.40750^{\circ}$ north and longitudes $00^{\circ} 51^{\prime} 12^{\prime \prime}$ and $0.85333^{\circ}$ west. It covers a total area of about $750 \mathrm{~km} 2$ (Ghana Statistical Service, 2010). It is specifically regarded as the fastest-growing city in the whole of West Africa (Abanka et al., 2009) and by its strategic location, Tamale has a market potential for local goods from the agricultural and commerce sectors from other districts in the region (Ghana Statistical Service, 2010) (Fig. 1). 


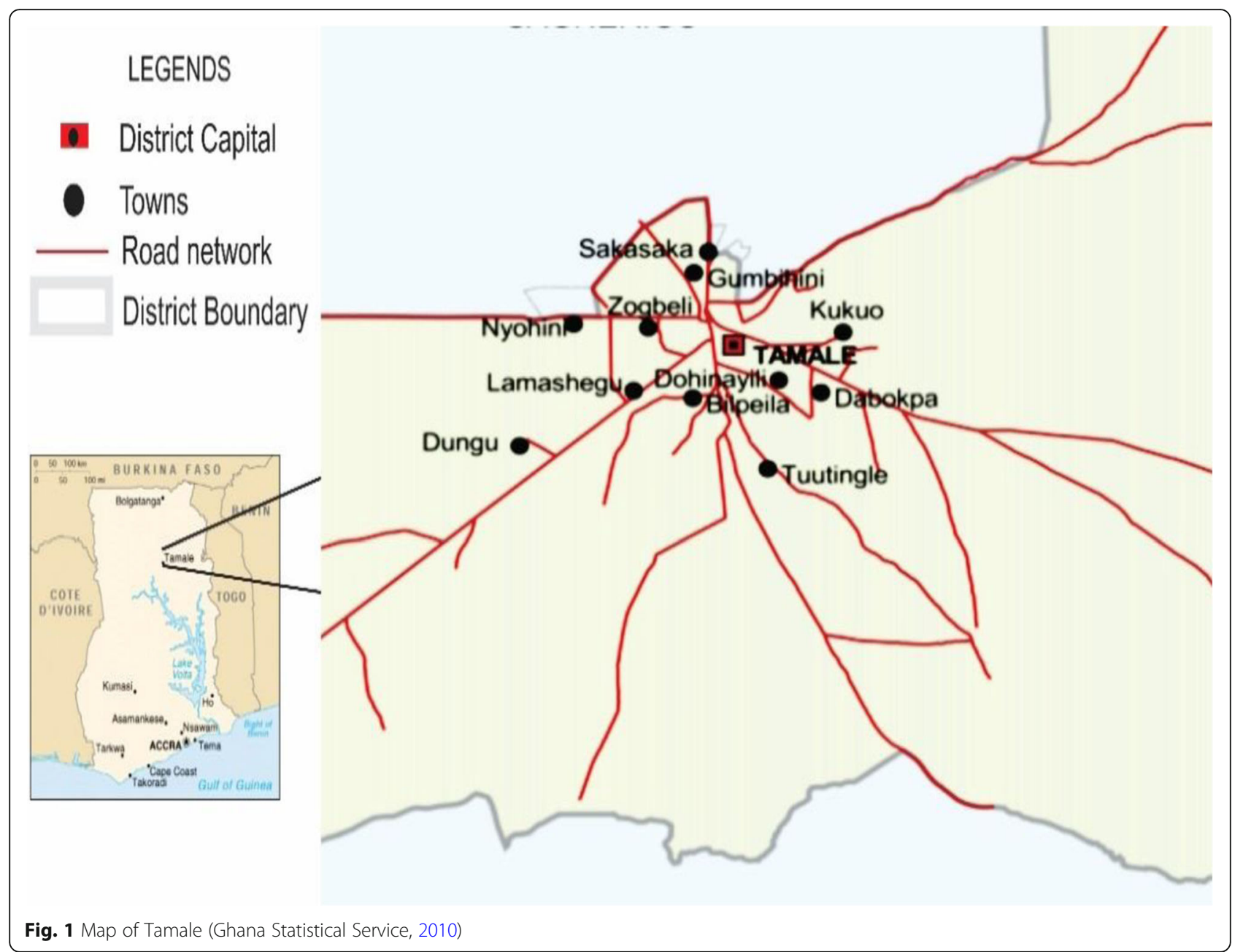

\section{Sample collection}

Stratified random sampling was implored based on the proximity of the food joints as well as sampling convenience, the study area was stratified into four zones/strata (zone1zone 4). Zone one (1) included areas such as the Timber market, Transport Yard and Nyohini, while Zone two (2) included; Zobgeli, Aboabo and Sabonjida. Localities that made up zone three (3) were; Changli, Taxi Rank, Bus Stop and Tishigu. Zone four (4) constituted; Moshie Zongo, Gumbihini and Parks and Gardens and its surroundings all in the Central Business District (CBD) in the Tamale Metroplis. The salads considered in this study composed of cabbage, lettuce, onions and tomatoes mixtures. A total of thirty (30) samples of ready-to-eat (pre-cut salads for ready consumption) mixture of salad vegetables (cabbage, lettuce, onions and tomatoes) vended at food joints in the CBD were collected from December, 2016 to February, 2017 using the stratified random sampling procedure. Specifically, based on the number of vendors of pre-cut salads in each zone demarcated, seven (7) samples were taken from zone 1 , nine (9) samples were taken from zone 2, eight (8) samples were taken from zone 3 and six (6) samples were taken from zone 4. Approximately, $200 \mathrm{~g}$ of salad vegetable mixtures from each vendor which are usually served directly to consumers were aseptically collected into sterile polythene zip lock bags, kept in ice chest, maintained at $0-4{ }^{\circ} \mathrm{C}$ and were then transported to the Spanish Laboratory Complex of the University for Development Studies, Nyankpala campus, Ghana processed within $2-4 \mathrm{~h}$ for microbial analysis.

\section{Microbial analyses and culture conditions}

All media were prepared in accordance with the manufacturer's protocol. Media used included. MacConkey agar (Oxoid Ltd., Basingstoke, Hampshire, England), Salmonella-Shigella agar. (Techno Pharmchem, India) Simmon Citrate Agar and MYP agar base. These were used for the. Isolation, growth and maintenance of microorganisms.

\section{Preparation of salad samples}

Twenty-five grams $(25 \mathrm{~g})$ of each salad sample was weighed and transferred into sterile polythene zip lock bags under a laminar flow hood (Envair, UK). Salad in each sterile bag was then mixed thoroughly with $225 \mathrm{ml}$ of buffered peptone water. This mixture was homogenized 
very well by simple "hand massaging" and constant shaking to obtain a uniform mixture (stock). Ten (10)-fold serial dilutions were also carried out at five (5) levels.

Specifically, $0.1 \mathrm{ml}$ each of $100,10-1,10-2,10-3,10-4$ and 10-5 dilutions were taken aseptically under the laminar flow hood and inoculated on a solidified MacConkey (Oxoid Ltd., Basingstoke and Hampshire, England), Salmonella-Shigella (Techno Pharmchem, India) and Mannitol Egg Yolk Polymyxin (MYP) agars. The inoculated plates were then inverted and incubated at $37^{\circ} \mathrm{C}\left(44.5^{\circ} \mathrm{C}\right.$ for MacConkey) for $24 \mathrm{~h}$.

After $24 \mathrm{~h}$ of incubation, bacterial colonies were identified based on the colour depicted by the colonies on each agar plate. Growth of pink colonies were depicted as Escherichia coli and growth of colourless colonies with black centres were depicted as Salmonella spp. and growth of colourless colonies without black centres were depicted as Shigella spp. based on description by Acumedia Manufacturers (2011). The growth of Bacillus cereus on M.Y.P agar plates were depicted as pink colonies. All bacteria colonies were enumerated in accordance with American Public Health Association APHA (American Public Health Association) (2008).

\section{Confirmatory tests (catalase/citrate tests)}

Catalase test was carried out for all the bacteria isolates. A drop of Hydrogen per Oxide was put on a glass slide. Colonies were picked with a sterile loop and added to the drop. Observation was made for bubbles production. Colonies that have catalase are able to break down Hydrogen per oxide into water and Oxygen, which can be seen in the form of air bubbles leaving the solution.

Citrate test was done were unique colonies were picked with a sterilized loop and streaked across the plates containing citrate media without breaking the agar and then incubated for $24 \mathrm{~h}$. Data was collected based on color change.

\section{Data analysis}

The analysis was carried out by descriptive statistics (finding means and standard deviations) and (ANOVA) of mean microbial counts among the four zones were also determined by checking for significant differences. Pearson's correlation analysis was also carried out to determine the correlation of bacterial loads among the four zones. (Genstat twelfth (12) edition and Microsoft excel software were used).

\section{Results and discussion}

\section{Prevalence of bacteria isolates in salad}

Vegetables such as salad vegetables after cultivations from the farm go through a series of handling processes and preparations before they are served to consumers. The present study shows variations in bacteria presence and levels in ready-to-eat vegetable salad mixtures obtained from the Business District of Tamale which may be attributed to the different hygienic practices by food vendors as well as the sources of cultivation from which these vegetables were obtained.

Out of 30 salad samples collected from the CBD, $E$. coli were detected in $29(96.7 \%)$ of them.

(Table 1). Also, 28 (93.3\%) samples of salad recorded positive for Bacillus cereus whilst the, and 23 (76.7\%) showed positive results for Shigella spp. (Table 1). Salmonella spp. were least prevalent with 22 (73.3\%) samples that indicated positive prevalence of the bacteria (Table 2).

\section{The mean count of bacteria in the salad samples}

The isolates obtained and the mean bacterial count of the various bacteria in the read to eat salads expressed as $\log 10 \mathrm{Cfu} / \mathrm{g}$ were as follows: Escherichia coli $(7.12 \pm$ 6.96), Bacillus cereus (7.22 \pm 7.12$)$, Shigella spp. (5.00 \pm 6.30) and Salmonella spp. (3.90 \pm 4.05$)$.

Table 3 presents the results of bacteria isolates with their mean values expressed in $\log 10 \mathrm{cfu} / \mathrm{g}$. The minimum count recorded for each bacterium was 0 whereas the maximum values ranged from 4.54 to $7.56 \log 10$ $\mathrm{cfu} / \mathrm{g}$. among the bacteria. E. coli count from the salad samples ranged from 0 to $7.56 \log 10 \mathrm{cfu} / \mathrm{g}$. with a mean of $7.12 \pm 6.96 \log 10 \mathrm{cfu} / \mathrm{g}$.. Bacillus cereus count from the salad samples ranged from 0 to $7.54 \log 10 \mathrm{cfu} / \mathrm{g}$ with a mean of $7.22 \pm 7.11 \log 10 \mathrm{cfu} / \mathrm{g}$. The study also showed that Shigella spp. count in the salad samples ranged from 0 to $5.44 \log 10 \mathrm{cfu} / \mathrm{g}$ with a mean of $5.04 \pm 6.30$.

Salmonella spp. count from the salad samples also ranged from 0 to $4.54 \log 10 \mathrm{cfu} / \mathrm{g}$. with a mean of 3.90 $\pm 4.05 \log 10 \mathrm{cfu} / \mathrm{g}$.

The elevated presence and levels may also be linked to contamination from the production source of the raw vegetables. This was affirmed by personal observation upon several visits to farms from which these salad vegetables were obtained, it was revealed that untreated waste water from storm drains was mainly used in irrigating the vegetables at the source of cultivation. This conclusion was due to the findings of Muinde and Kuria (2005), who indicated that contamination of most vegetables by bacteria is usually as a result of grey water (waste water generated from bathroom, kitchen and laundry used in the cultivation of these vegetables. The presence of $E$. coli in food samples was an indication of faecal contamination and improper hygienic practices by food vendors (Bakobie et al., 2017). Some strains of $E$. coli when in food could cause gastroenteritis and diarrhea in humans when ingested (Akter, 2016). Adams and Moss (2008) established that E. coli do not usually lead to foodborne illness in humans but can however cause diarrhea in children in less developed countries. In a related study, Boateng (2014) reported 64\% contamination of products of vegetable origin (pepper/ tomatoes sauce) 
Table 1 Microbiological assessment of salad samples collected from local food joints

\begin{tabular}{|c|c|c|c|c|c|c|c|c|c|}
\hline \multirow{2}{*}{ Site } & \multirow[b]{2}{*}{ Sample } & \multirow[b]{2}{*}{ Condition } & \multirow[b]{2}{*}{ TBC cfu/ml } & \multicolumn{2}{|c|}{ Microbial Count } & \multirow[b]{2}{*}{ TSC cfu/ml } & \multirow[b]{2}{*}{ Bacillus spp } & \multicolumn{2}{|l|}{ Occurrence } \\
\hline & & & & TSsC cfu/ml & E. coli cfu/ml & & & Salmonella spp. & E.coli \\
\hline Zone 1 & $1 \mathrm{~F}$ & Semi-closed & TNTC & TFTC & $9.2 \times 10^{6}$ & 0 & + & + & + \\
\hline Zone 1 & $2 \mathrm{R}$ & Opened & TFTC & 0 & $1.51 \times 10^{7}$ & 0 & + & - & + \\
\hline Zone 1 & $3 \mathrm{H}$ & opened & TNTC & $1.45 \times 10^{4}$ & $5.7 \times 10^{6}$ & 0 & + & + & + \\
\hline Zone 2 & $4 \mathrm{~F}$ & Semi-closed & TNTC & $1.18 \times 10^{4}$ & $2.15 \times 10^{7}$ & 0 & + & + & + \\
\hline Zone 1 & $5 \mathrm{R}$ & Semi-closed & 0 & $4.1 \times 10^{3}$ & $2.15 \times 10^{7}$ & 0 & - & + & + \\
\hline Zone 1 & $6 \mathrm{R}$ & Semi-closed & 0 & 0 & $1.46 \times 10^{7}$ & 0 & - & - & + \\
\hline Zone 1 & $7 S$ & Semi-closed & TNTC & 0 & $1.55 \times 10^{7}$ & 0 & + & - & + \\
\hline Zone 1 & $8 \mathrm{~S}$ & Semi-closed & TNTC & TNTC & $2.79 \times 10^{7}$ & TFTC & + & + & + \\
\hline Zone 2 & $9 \mathrm{H}$ & opened & TNTC & TNTC & $1.44 \times 10^{7}$ & $7.1 \times 10^{3}$ & + & + & + \\
\hline Zone 2 & $10 \mathrm{H}$ & Semi-closed & $1.18 \times 10^{7}$ & 0 & $1.98 \times 10^{7}$ & $7.9 \times 10^{3}$ & + & - & + \\
\hline Zone 2 & $11 \mathrm{H}$ & Semi-closed & $1.3 \times 10^{7}$ & TFTC & $3.8 \times 10^{6}$ & $4.0 \times 10^{3}$ & + & + & + \\
\hline Zone 2 & $12 \mathrm{H}$ & opened & TNTC & $2.0 \times 10^{4}$ & TNTC & $8.1 \times 10^{3}$ & + & + & + \\
\hline Zone 2 & $13 \mathrm{H}$ & Semi-closed & TFTC & $5.4 \times 10^{3}$ & $1.26 \times 10^{7}$ & $1.1 \times 10^{4}$ & + & + & + \\
\hline Zone 2 & $14 \mathrm{H}$ & opened & TNTC & 0 & $1.52 \times 10^{7}$ & $7.2 \times 10^{3}$ & + & - & + \\
\hline Zone 2 & $15 \mathrm{~S}$ & Semi-closed & $9.7 \times 10^{6}$ & 0 & $1.38 \times 10^{7}$ & $1.04 \times 10^{4}$ & + & - & + \\
\hline Zone 2 & $16 \mathrm{H}$ & Semi-closed & TNTC & $5.5 \times 10^{3}$ & TNTC & $7.3 \times 10^{3}$ & + & + & + \\
\hline Zone 3 & $17 \mathrm{~F}$ & Semi-closed & $9.0 \times 10^{6}$ & $3.4 \times 10^{3}$ & $1.56 \times 10^{7}$ & TFTC & + & + & + \\
\hline Zone 3 & $18 \mathrm{H}$ & opened & $1.83 \times 10^{7}$ & 0 & $4.7 \times 10^{6}$ & $8.1 \times 10^{3}$ & + & - & + \\
\hline Zone 3 & $19 \mathrm{H}$ & opened & $3.1 \times 10^{6}$ & TFTC & $6.5 \times 10^{6}$ & $9.2 \times 10^{3}$ & + & + & + \\
\hline Zone 3 & $20 \mathrm{~s}$ & Semi-closed & $7.4 \times 10^{6}$ & $1.17 \times 10^{4}$ & $9.9 \times 10^{6}$ & TNTC & + & + & + \\
\hline Zone 3 & $21 \mathrm{~F}$ & opened & TFTC & TFTC & TFTC & $1.61 \times 10^{4}$ & + & + & + \\
\hline Zone 3 & $22 \mathrm{~F}$ & Semi-closed & $1.08 \times 10^{7}$ & TFTC & $8.3 \times 106$ & $1.40 \times 10^{4}$ & + & + & + \\
\hline Zone 3 & $23 \mathrm{~S}$ & Semi-closed & $2.12 \times 10^{7}$ & TFTC & $7.0 \times 10^{6}$ & TNTC & + & + & + \\
\hline Zone 3 & $24 \mathrm{H}$ & opened & $1.07 \times 10^{7}$ & $1.36 \times 10^{4}$ & $4.0 \times 10^{6}$ & TNTC & + & + & + \\
\hline Zone 4 & $25 \mathrm{H}$ & opened & $4.4 \times 10^{6}$ & TFTC & TFTC & TNTC & + & + & + \\
\hline Zone 4 & $26 \mathrm{H}$ & Semi-closed & $1.2 \times 10^{7}$ & $8.4 \times 10^{3}$ & TFTC & $3.5 \times 10^{3}$ & + & + & + \\
\hline Zone 4 & $27 \mathrm{H}$ & opened & $1.43 \times 10^{7}$ & 0 & TFTC & $4.9 \times 10^{3}$ & + & - & + \\
\hline Zone 4 & $28 \mathrm{~S}$ & opened & $2.4 \times 107$ & TNTC & TFTC & TFTC & + & + & + \\
\hline Zone 4 & $29 R$ & opened & $2.21 \times 10^{7}$ & TNTC & 0 & $2.96 \times 10^{4}$ & + & + & - \\
\hline Zone 4 & $30 \mathrm{R}$ & open & TNTC & TNTC & $4.3 \times 10^{6}$ & $1.15 \times 10^{4}$ & + & + & + \\
\hline
\end{tabular}

Total Bacillus spp. Count (TBC), Total Salmonella spp. Count (TSsC), Total Shigella spp. Count (TSC) E. coli count (E. coli). TNTC (too numerous to count) > 300. TFTC (too few to count) < 30 counts. R (Rubber), S (Spoon), H (Hands), F (Tongs)

Table 2 Summary of Prevalence of Bacteria isolates in 30 salad samples collected

\begin{tabular}{lll}
\hline Bacteria & No of Samples $(+)$ & Percentage (\%) \\
\hline Escherichia coli & 29 & $96.70 \%$ \\
Bacillus cereus & 28 & $93.30 \%$ \\
Shigella spp & 23 & $76.70 \%$ \\
Salmonella spp & 22 & $73.30 \%$ \\
\hline
\end{tabular}

Positive occurrence (+) with E. coli in Kumasi. Similarly, Bonah (2014) also reported the presence of $E$. coli in $66.6 \%$ of sampled readyto-eat tomatoes sauce in the Tamale Metropolis.

According to guidelines from the Health Protection Agency (2009) E coli load in $25 \mathrm{~g}$ of ready-to-eat vegetables $>10^{2} \mathrm{cfu} / \mathrm{g}$ is categorized as unwholesome for human consumption however the vegetables will be categorized as satisfactory if the load in $25 \mathrm{~g}$ is $<20 \mathrm{cfu} / \mathrm{g}$, therefore, all $96.7 \%$ (29) of samples that indicated the presence of E. coli were all considered unsatisfactory for consumption with only 1 sample representing 3.3\% which was satisfactory. This contradicts that of Coulibali-Kalpy et al. (2017), who 
Table 3 Guidance on the interpretation of results for specific food-borne pathogens in ready-to-eat food in general (colony-forming unit (cfu)/g)

\begin{tabular}{llll}
\hline Criterion & Satisfactory & Borderline & $\begin{array}{c}\text { Unsatisfactory (potentially injurious } \\
\text { to health and/or unfit for human } \\
\text { consumption) }\end{array}$ \\
\hline $\begin{array}{l}\text { Escherichia coli O157 (and other Shiga } \\
\text { toxin-producing E. coli (STEC)) }\end{array}$ & n.d. in $25 \mathrm{~g}$ & N/A & Detected in $25 \mathrm{~g}$ \\
$\begin{array}{l}\text { Salmonella spp. } \\
\text { Shigella spp. }\end{array}$ & n.d. in $25 \mathrm{~g}$ & $\mathrm{~N} / \mathrm{A}$ & Detected in $25 \mathrm{~g}$ \\
$\begin{array}{l}\text { Bacillus cereus } \\
\text { Hygiene indicator organism }\end{array}$ & n.d. in $25 \mathrm{~g}$ & $\mathrm{~N} / \mathrm{A}$ & Detected in $25 \mathrm{~g}$ \\
& Satisfactory & $10^{3}$ to $<10^{5}$ & $>10^{5}$ \\
Escherichia coli & & Borderline & Unsatisfactory (potentially injurious \\
to health and/or unfit for human \\
consumption)
\end{tabular}

Source: Health Protection Agency, 2009. Guidelines for Assessing the Microbiological Safety of Ready-to-Eat Foods Placed on the Market. http://www.gov.uk/phe. (Accessed 4 March 2017)

reported $94 \%$ of some raw vegetables including pre-cut salads samples contaminated with $E$. coli as Satisfactory for consumption in their study carried out in Cote d'Ivoire.

The study also revealed that there was a significant difference in the mean counts of $E$. coli among the four zones which suggests that $E$. coli contamination was influenced by the location or zone in which sampling was done (Fig. 2). This finding is in contrast to that of Bakobie et al. (2017), who noted that there was no significant difference in pathogenic bacteria in spices sampled from four sites in the CBD of Tamale.

Studies showed that Bacillus cereus was recorded in almost every friendly environment.

(Samapundo et al., 2011). Salads contamination with Bacillus cereus might have resulted also from the source of production of the vegetables based on the nature of water used in irrigating them, contamination of salads vegetables from coming into contact with soils and also using contaminated utensils during the preparation of salads. Akusu et al. (2016) reported that the raw materials for salad making often come into contact with soil and thus improper washing with water may result in high human health risk. The present study established the presence of Bacillus cereus in salad samples in the study area. This could be attributed to the improper treatment of raw materials for salad preparation which could lead to the contamination of these vegetables by Bacillus cereus (Ghosh et al., 2007). This finding corroborates CoulibalyKalpy et al. (2017) who attributed contamination of food to contaminated utensils coming in contact with vegetables.

Out of the total number of salad samples collected 83.3\% were unsatisfactory for consumption. Whilst $16.7 \%$ were classified as satisfactory according to the guidelines stipulated by the Health Protection Agency

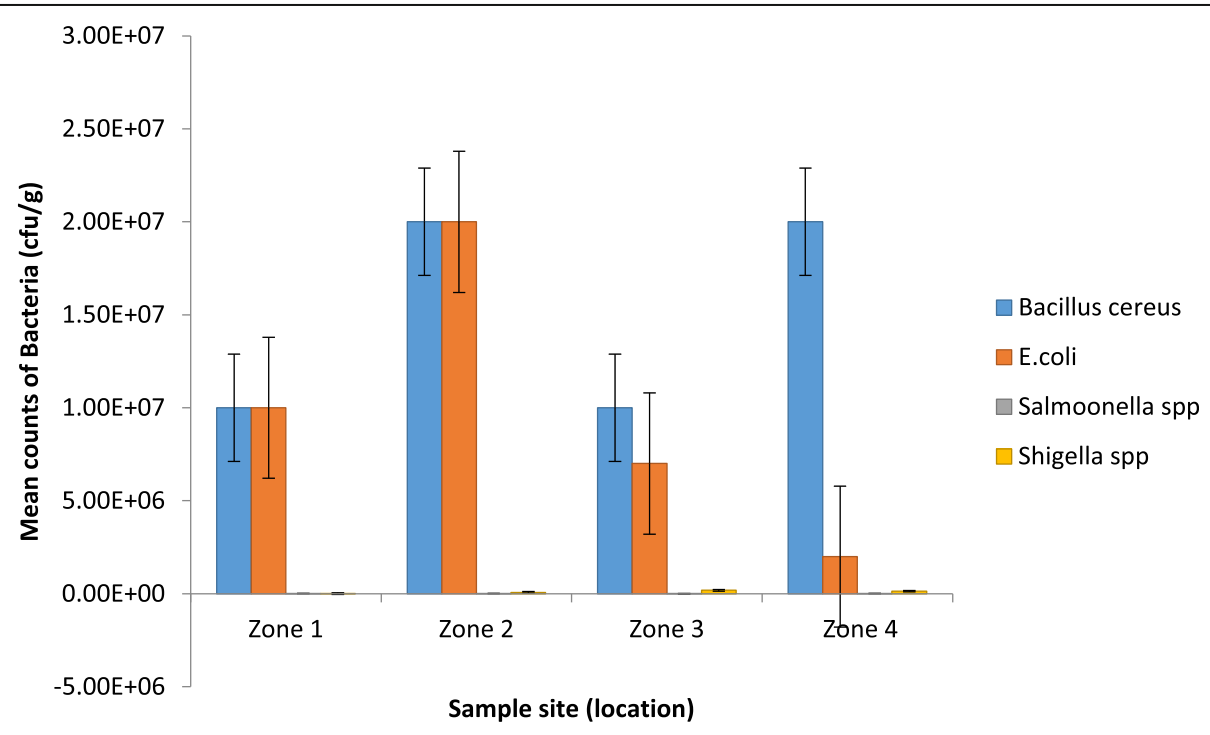

Fig. 2 Mean count of bacteria across four zones in the business district of Tamale 
(2009) which provides that in $25 \mathrm{~g}$ of sampled ready-toeat vegetables, Bacillus cereus load of $>10^{5} \mathrm{cfu} / \mathrm{g}$ is described as unsatisfactory for human consumption whereas a load of $<10^{3} \mathrm{cfu} / \mathrm{g}$ is described as satisfactory.

Comparatively, this study recorded the highest occurrence of Bacillus cereus in food compared to Mensah et al. (2002) who sampled 511 different food samples and reported that $5.5 \%$ of samples tested positive for Bacillus cereus. In a related study, Umoh and Odoba (1999) reported $26 \%$ contamination of street food samples in Nigeria.

However, statistical analysis revealed that Bacillus cereus counts varied significantly across the four zones $(p=0.02)$ (Fig. 2).

This present study has shown the presence of Salmonella spp. in salad samples. It is stipulated by.

Health Protection Agency (2009) and the Food and Drugs Board (2013) that Salmonella spp. Should not be detected in $25 \mathrm{~g}$ of ready to eat foods in order to be satisfactory for human consumption otherwise it should described as unsatisfactory. Following these guidelines, all samples of salad that indicated the presence of Salmonella spp. (73.3\%) were described as unsatisfactory for human consumption. Salmonella spp. presence in food depicts a greater human health risk for consumers of such contaminated foods. The bacterium is mostly associated with cross contamination of food products especially from eggs and egg products National Institute of Allergy and infectious Disease NIAID (2002). The incidence of Salmonella spp. in food is generally associated with cross-contamination and also depended on irregular time temperature chain (Mashak et al., 2015). Salmonella is mostly implicated in most food borne diseases (Bakobie et al., 2017).

The detection of Salmonella spp. may be attributed to poor hygiene practices by the vendors.

(Bakobie et al., 2017) since most vending premises were not kept tidy enough and could have also resulted from cross-contamination of the food substances. The high Salmonella spp. load in the present study perhaps could also have resulted from contamination through the value chain thus beginning from the production sites. The present study recorded higher incidence of Salmonella spp. in food samples compared to that of Boateng (2014) who detected the presence of Salmonella spp. in $32 \%$ samples of pepper/ sauce.

In contrast to this, Amoah (2014) did not detect Salmonella spp. in all salad samples collected and studied in Kumasi. Mensah et al. (2002) also analysed kenkey samples in Accra and recorded zero prevalence for Salmonella spp. This was attributed to the high acidity associated with kenkey which inhibits microbial growth (Mensah et al., 2002). Again, a study by Mutsuddy (2016) contrast the findings of this present study in which all street food samples were free from Salmonella spp.
Statistical analysis revealed that there was no significant difference in mean counts of salmonella spp. across the four zones demarcated in the present study since $p$ value $>0.05$ (Fig. 2). Hence, the contamination across the zones was similar as a result of similar contributing factors in the zones. This finding is in agreement with that of Bakobie et al. (2017) who in their study reported that there was no significant difference in pathogenic bacteria count in sampled spices from four different locations in the central part of Tamale.

The present study has established the presence of Shigella spp. in salad samples obtained from the Central Business District of Tamale. The present study has established the presence of Shigella spp. in salad samples obtained from the business district of Tamale. A study by Mutsuddy (2016) also isolated Shigella spp. in 3\% of street vended foods in Dhaka city in Bangladesh.

The Health Protection Agency (2009) stipulated that ready-to-eat foods are satisfactory for consumption if Shigella spp. is not detected in $25 \mathrm{~g}$ of the food sample and unsatisfactory for consumption if Shigella spp. is detected in $25 \mathrm{~g}$ of ready-to-eat food including pre-cut salads. Per this guideline, all the samples $(76.7 \%)$ that showed the presence of the bacterium were unwholesome for human consumption. The presence of Shigella spp. in salads might be due to unsanitary practices and lack of hygiene practices on the side of the food vendors in the Business District. Amissah and Owusu (2012) reported that the level and magnitude of sanitary practices/hygienic practices by food vendors can have great influence on the bacterial load in street vended foods.

The absence of Shigella spp. in some samples suggests proper hygienic practices on the part of the handlers (Rane, 2011). Sources of the salad vegetables could also have influenced the higher.

Shigella spp. load in some samples.

Also, the study also established the mean counts of Shigella spp. varied significantly across the four zones demarcated in the business district of Tamale $(p<0.05)$ (Fig. 2). This implies different factors that might have contributed to the contamination in each zone. The recent study has effectively indicated higher incidence and bacterial load of E. coli, Bacillus cereus, Salmonella and shigella spp. in ready to eat vegetable salads sampled. This conclusion affirms the findings of Akusu et al. (2016) who recorded higher bacterial load for vegetable salads among various street foods collected in Port Harcourt Metropolis in Nigeria.

\section{Correlation matrix}

Correlation analysis revealed that $E$. coli in zone 1 (zone1e) correlated positively and significantly with Shigella spp. in Zone 3 (zone3 sh) at 5\% significant level (0.876). On the other hand, Shigella. 
Table 4 Correlation Analysis on Bacteria Isolates across the Four Zones Studied

\begin{tabular}{lllllll}
\hline & zone1e & zone2e & zone2b & zone2s & zone2sh & zone3e \\
\hline zone1e & 1 & & & & & \\
zone2e & -0.394 & 1 & 1 & & & \\
zone2b & 0.266 & 0.556 & 0.400 & 1 & & 1 \\
zone2s & -0.200 & 0.271 & -0.446 & -0.129 & & 1 \\
zone2sh & 0.124 & 0.029 & 0.038 & -0.219 & $-.779^{b}$ & -0.323 \\
zone3e & -0.148 & -0.297 & -0.141 & -0.553 & 0.324 & 1 \\
zone3sh & $.876^{\mathrm{a}}$ & -0.426 & & & & \\
\hline
\end{tabular}

${ }^{a}$ Correlation is significant at the 0.01 level (2-tailed)

${ }^{\mathrm{b}}$ Correlation is significant at the 0.05 level (2-tailed)

Note (Legend): zone1e (zone 1 E .coli), zone2e (zone 2 E. coli), zone2b (zone 2 Bacillus cereus), zone 2 s (zone 2 Salmonella spp.), zone 2 sh (zone 2 shigella spp.), zone3e (zone 3 E. coli), zone3b (zone 3 Bacillus cereus), zone 3 sh (zone 3 shigella spp.) (Table IV). Correlation matrix on the four zones in terms of the bacteria isolates revealed that a positive and significant correlation existed between E. coli in Zone 1 and Shigella spp. in Zone 3. These findings imply that E. coli and Shigella spp. in the two Zones came from similar sources of contamination and have a strong relationship. However, Shigella spp. in Zone 2 negatively but significantly correlated with $E$. coli in Zone 3 . These results imply that Shigella spp. and E. coli in the two zones may have resulted from different sources of contamination since the correlation was showing a negative relationship. The results of the correlation matrix from the present is in contrast to the result established by Bakobie et al. (2017) who found no interrelationship between the various bacteria identified in their study in Tamale

spp. in Zone 2 (zone2 sh) correlated negatively but significantly with $E$. coli in Zone 3 (zone3 e) at $1 \%$ significant level (-0.779). The above information is illustrated in the table below (Table 4).

\section{Conclusion}

The study sought to determine the microbial quality of pre-cut ready-to-eat vegetable salads sold by food vendors in the Central Business District of the Tamale Metropolis. The incidence of food borne illness is increasing each day in Ghana. In the present study, Escherichia coli was present in $96.7 \%$ of the salad samples collected, Bacillus cereus was present in $93.3 \%$ of salad samples whereas Salmonella spp. and Shigella spp. were present in 73.3 and $76.5 \%$ of salad samples respectively.

The present study revealed that ready-to-eat salads sold by street food vendors in the Business.

District of Tamale constitutes a likely health risk to consumers in terms of microbial quality. The contamination could be attributable to improper food handling, unhygienic food preparation and processing, source contamination of the vegetables from production sites and generally along the value chain and environmental conditions. This study shows there is the urgent need for the improvement in food safety and quality standards of ready-to-eat foods in the Business District of Tamale.

Based on the findings of this study, the following are recommended:

1. Further research should be carried out on salad to determine the antimicrobial susceptibility of the bacteria identified.

2. Further research should be carried out on salad to isolate specific pathogenic strains of the bacteria identified in this present study.

\section{Abbreviations}

APHA: American Public Health Association; CBD: Central Business District: CDC: Centre for Disease Control; Cfu/g: Colony Forming Units per Grams; FAO: Food and Agriculture Organisation; GFDB: Ghana Food and Drugs Board; GNA: Ghana News Agency; GSS: Ghana Statistical Service; HACCP: Hazard Analysis Critical Control point; ICMSF: International Commission for Microbiological Specifications; MOFA: Ministry of Food and Agriculture; MYP: Mannitol Egg Yolk Polymyxin; NIAID: National Institute of Allergy and Infectious Disease

\section{Acknowledgements}

we extend our utmost thanks to the almighty God for His guidance and protection as well as His many favors and blessings bestowed on as throughout the study.

We are equally enormously indebted to the lecturers of the Department of Ecotourism and Environmental Management (DEEM) for the various roles they played.

Finally, we express our gratitude to the families of the authors for their continue support throughout the study.

\section{Funding}

Not applicable

\section{Availability of data and materials}

We solemnly hereby declare that this present work submitted to International Journal of Food.

Contamination is the results of our own research and that this article has never been presented anywhere for publication. Works by others which served as a source of information have been duly referenced.

\section{Authors' contributions}

the principal author (Abakari Godwin) was the one who conducted the laboratory analyses. He also researched on the topic and came out with the relevant literature for the write-up. The second author (Cobbina Samuel Jerry) supervised the study from start to finish and he was also responsible for all the necessary corrections in the write-up. The third author. (Yeleliere Enoch) assisted in carrying-out the experiment, assemblage of the write-up and making the needed corrections as well as submitting it to a suitable journal for publication. All authors read and approved the final manuscript.

\section{Competing interest}

The authors declare that they have no competing interests.

\section{Authors' information}

Mr. Abakari Godwin holds a BSc in Natural Resources and Environment and majored in Ecotourism and Environmental Management from the University 
for Development Studies. He is a Research Assistant in the same University under the faculty of Natural Resources and Environment. Dr. Samuel J. Cobbina is a Senior Lecturer and Vice Dean of the Faculty of Natural Resources and Environment of the University for Development Studies. He has a PhD in Environmental Science and Engineering from Jiangsu University and an MPhil in Environmental Science from the University of Ghana. He has research and teaching experience spanning a period of thirteen years in the field of Water Quality Monitoring and Assessment. He has several publications in referred journal. He has been the principal researcher in various projects such as the UNICEF funded studies on hand washing with soap (HWWS) in basic schools in the northern region of Ghana and the CIDA-funded FARMER project on the Quality of water in dugouts in northern Ghana. He is currently a member of a research team assessing the environmental and human health impacts of oil and gas activities on frontline communities in Ghana.

Mr. Yeleliere Enoch holds BSc in Renewable Natural Resources option in Ecotourism and Environmental management from the University for Development Studies. He is a research Assistant in Faculty of Natural Resources and Environment, University for Development Studies.

Received: 19 September 2017 Accepted: 1 February 2018 Published online: 10 February 2018

\section{References}

Ababio FW, Lovatt P. A revie on food safety and food hygiene studies in Ghana. 2014.

Abankwa V, Grimard A, Somer Kuria F (2009) United Nations Human Settlements Programme (UNIHABITAT) Available : www. Unhabitat.org/pmss/ getElectronicVersion.aspx?nr =2929. Accessed on 9 Sept 2016.

Acumedia Manufacturers. MacConkey agar and salmonella shigella agar: Neogen Corporation; 2011. p. 1-47.

Adams MR, Moss MO (2008) Bacterial agents of foodborne illness. Food Microbilogy. $3^{\text {rd }}$ edn. Cambidge, UK, the Royal Society of Chemistry, pp. 182-268.

Akter N (2016)"Study on Bacteriological Quality of Street-vended Foods Collected from Different Private Universities in Dhaka City, Bangladesh". A Dissertation Submitted to East West University, Dhaka, Bangladesh in Partial Fulfillment of Requirements for the Degree of Bachelor of Pharmacy. Department of Pharmacy, East West University.

Akusu OM, Kiin-Kabari DB, Wemedo SA. Microbiological quality of selected street vended foods in Port Harcourt metropolis, rivers state, Nigeria. Sky J Food Sci. 2016;5(2):008-11.

Alimi BA, Oyeyinka AT, Olohungbebe LO. Socio-economic characteristics and willingness of consumers to pay for the safety of furadenunu in Ilorin, Nigeria. Qual Assur Saf Crops Foods. 2016:81-6.

Amissah A, Owusu J. Assessing the microbiological quality of foods sold on and around Koriforidua polytechnic campus in Ghana. Annals Food Science and Technology. 2012;13(1):60-7.

Amoah D (2014) Microbial risk assessment of mixed vegetable salads from selected canteens in the Kumasi metropolis, Ghana. Pp 41-56.

Amoah P, Drechel P, Abaidoo RC, Ntow WJ. Pesticide and pathogen contamination of vegetables in Ghana's urban markets. Arch Environ Contam Toxicol. 2006;50:1-6.

APHA (American Public Health Association) (2008) Standard methods for the examination of water and wastewater (19th Edition). American Public Health Association (APHA), Washington, DC Microbiological Quality of selected street vended foods in Port Harcourt metropolis, Rivers State, Nigeria C.

Bakobie N, Addae AS, Duwiejuah AB, Cobbina SJ, Miniyila S. Microbial profile of common spices and spice blends used in tamale, Ghana. Int J Food Contam. 2017:4(10):1-5.

Boateng AE (2014) "Assessment of food hygiene practices by street food vendors and microbial quality of selected foods sold". A study at Dunkwa-On-Offin, Upper Denkyira East municipality of the Central Region. A thesis submitted to the department of community health, college of health sciences in partial fulfillment of the requirements for the degree of MSc. public health. KNUST.

Bonah E (2014) "Heavy metal health risk assessment and microbial quality of locally milled ready-to-eat tomato in tamale, Ghana". A thesis submitted to the institute of distance learning, Kwame Nkrumah University of science and technology in partial fulfillment of the requirements for the award of Master of Science degree (M.Sc. food quality management). KNUST.

Bruce J, Boschi- Pinto C, Shibuya K, Black R. WHOs estimates of the causes of death in children. Lancet. 2005;365:1147-52.
Centre for Disease Control and Prevention (CDC). "Salmonellosis." Division of Foodborne, Bacterial, and Mycotic Diseases. Department of Health and Human Services. 2008.

Centers for Disease Control and Prevention (2014) Antibiotic Resistance Threats in the United States, 2013. Available at: https://www.cdc.gov/drugresistance/ pdf/ar-threats-2013-508.pdf. Accessed 21 Apr 2016.

Choudhury M, Mahanta L, Goswami J, Mazumder M, Pegoo B. Socio- economic profile and food safety knowledge and practice of street food vendors in the city of Guwahati Assam, India. Food Control. 2011;22:196-203.

Coulibaly-Kalpy J, Agbo EA, Dadie TA (2017) Microbiological quality of raw vegetables and ready to eat products sold in Abidjan (Côte d'Ivoire) markets. Afr J Microbiol Res. Cote d'Ivoire, 11(10): pp 204-210.

De Oliveira MA, de Souza VM, Bergamini AMM, De Martinis ECP. Microbial quality of ready-to-eat minimally processes vegetables consumed in Brazil. Food Control. 2011:22(8):1400-3.

Estrada-Garcia T, Cerna JF, Thompson MR, Lopez-Saucedo C. Faecal contamination and enterotoxigenic Escherichia coli in street-vended chilli sauces in Mexico and its public health relevance. Epidemiol Infect. 2002;129:223-6.

Feglo P, Sakyi K. Bacterial contamination of street vending food in Kumasi, Ghana. Journal of medical and biochemical sciences. Food Control. 2012;1(1): 1-8. 47: 92-97

Foskett P, Ceserani V, Kinton, R (2003) The theory of catering. 10th ed. Hodder and Stoughton. London. p. 531.

Ghana Statistical Service (2010) Population and housing census Ghana.

Ghosh M, Wahi S, Kumar M, Ganguli A (2007) Prevalence of enterotoxigenic Staphylococcus aureus and Shigella spp. in some raw street vended Indian foods.

Health Protection Agency. Guidelines for Assessing the Microbiological Safety of Ready-to-Eat Foods Placed on the Market. 2009. http://www.hpa.org.uk/webc/ HPAwebFile/HPAweb_C/1259151921557.

Henseler M (2005) Lettuce Survey, Investigation of lettuce distribution channels and characterization of lettuce sellers and consumers, in order to identify target populations for risk reduction programs, Project Report, Market analysis component of CP51, IWMI, West Africa Office, 2005

Mashak Z, Langoodi AM, Ehsani A, Fathabad AE, Ilkhanipoor A. Microbiological quality of ready-to-eat foods of Tehran Province. Vol.9(5). Afr J Food Sci. 2015:257-61.

Mensah P, Manu DY, Darko KO, Ablordey A. Streets foods in Accra, Ghana: how safe are they? Bull World Health Org. 2002;80(7):546-54.

Muinde OK, Kuria E. Hygienic and sanitary practices of vendors of street foods in Nairobi, Kenya. Afr J Food Agric Nutr Dev. 2005;5:1-14.

Mutsuddy S (2016) Isolation and Identification of enteric bacteria in different street vended foods collected from different private universities in Dhaka city, Bangladesh.

National Institute of Allergy and infectious Disease NIAID. Foodborne disease Bethesdo, MD20892-2520. Nigeria. Food Control. 2002;10:9-14.

Ntuli V, Peter C, Kwiri R (2017) Microbiological quality of selected dried fruits and vegetables in Research, pp 1-5.

Olsen M. Risk, Awareness of street food vendors and consumers - a qualitative study of practices and perceptions related to lettuce consumption in street food in Kumasi, Ghana. Individual study course, Institute of Public Health, University of Copenhagen, IWMI and KNUST. 2005.

Ramteke A, Khanuja SK, Chandrakar OP, Gupta T. Survival benefits dominate the whole life risk coverage among the rural population of Raipur postal division of Chhattisgarth state. Int J Res Sci Manage. 2016;3(5):23-6.

Rane S. Street vended food in developing world: hazard analyses. Indian J Microbiol. 2011;51(1):100-6.

Saba CKS, Gonzalez-Zorn B. Microbial food safety in Ghana: a meta-analysis. Article J Infect Dev Ctries. 2012;6(12):828-35.

Sabbithi A, Kumar RN, Kashinath L, Bhaskar V, Rao VS. Microbiological quality of salads served along with street foods of Hyderabad, India. Int J Microbilogy. 2014:2014(10):1.

Samapundo S, Everaert H, Wandutu JN, Rajkovic A, Uyttendaele M, Devlieghere F. The influence of headspace and dissolved oxygen level on growth and haemolytic BL enterotoxin production of a psychrotolerant bacillus weihenstephanensis isolate on potato based ready-to-eat food products. Food Microbiol. 2011;28:298-304.

Umoh VJ, Odoba MB (1999) Safety and quality evaluation of street foods sold in Zaria. WHO/FAO (2015) Assuring Food Safety and Quality: Guidelines for Strengthening National Food Control Systems. Food and Nutrition Paper No. 76. 